\title{
DEMAND PATTERNS, DEMOGRAPHIC CHANGE AND ECONOMIC GROWTH *
}

\author{
Allen C. Kelley
}

I. Introduction, 110. - II. The model, 112. - III. The model and Philippine experience, 115. - IV. Demand patterns, demographic change, and economic growth, 120. - V. Implications and conclusions, 124. - Appendix, 125.

\section{INTRODUCTION}

One of the most widely observed and pervasive trends associated with the process of economic development is the rise in the importance of industrial production which accompanies an expansion in per capita income. ${ }^{1}$ At the same time, primary production declines as a share of total output.

The theoretical explanation of this observed pattern of economic growth typically focuses on Engel's law: food expenditures occupy a declining proportion of household budgets as income rises. ${ }^{2} \mathrm{By}$ inference, nonfood expenditures plus savings will tend to increase in relative importance.

Based in part on these "basic laws of economics," the development strategy of hastening the shift in the center of production from agriculture to secondary activity is frequently cited as a policy which is consistent with the "natural course" of consumption trends and

* The author wishes to acknowledge the helpful suggestions of Irma Adelman, Hollis Chenery, John Conlisk, Theodore Morgan, James Knowles, Burt Weisbrod, and Jeffrey Williamson.

1. L. H. Bean, "International Industrialization and Per Capita Income," Studies in Income and Wealth, Vol. 8, National Bureau of Economic Research (New York, 1946). Hollis B. Chenery, "Patterns of Industrial Growth," American Economic Review, L (Sept. 1960), 624-54. C. Clark, The Conditions of Economic Progress (3d ed.; London: Macmillan, 1957). Republic of the Philippines, Department of Commerce and Industry, Bureau of the Census and Statistics, Census of the Philippines: 1960, Population, Housing (Manila, 1962). W. G. Hoffmann, The Growth of Industrial Economics, trans. W. O. Henderson and W. H. Chaloner (Manchester, England: Manchester University Press, 1958).

2. R. G. D. Allen and A. L. Bowley, Family Expenditures (London: P. S. King, 1935). E. Engel, "Die Productions- und Consumptionsverhaltnisse des Konigreichs Sachsen," Zeit schrift des Statistischen Bureaus des Koniglich Sachsischen Ministerium des Inneren (Nov. 1957, Nos. 8 and 9). L. M. Goreux, Income Elasticity of the Demand for Food (Rome: Economic Commission for Europe, 1959). H. S. Houthakker, "An International Comparison of Household Expenditure Patterns, Commemorating the Centenary of Engel's Law," Econometrica, Vol. 25 (Oct. 1957), pp. 531-51. Nurul Islam, Studies in Consumer Demand, Bureau of Economic Research, Dacca University (Karachi, 1965). C. E. V. Leser, "Forms of Engel Functions," Econometrica, Vol. 31 (Oct. 1963), pp. 694-703. 
economic development. Unfortunately, the uncritical application of this set of theoretical ideas may be based on a misinterpretation of the factors explaining the widely observed patterns of industrial growth.

On the one hand, Chenery has argued that the almost exclusive attention to the demand forces operative in explaining industrial patterns has resulted in overlooking supply factors, that is, the changes in comparative advantage in production which derive from alterations in technology and factor endowments. ${ }^{3}$ Based on a cross-section analysis of fifty-one countries, he concludes that the major influences shaping industrial patterns are not the determinants of final demand (including exports), but rather those of supply.

On the other hand, even when the demand factors are considered separately, we argue below that the Engel curve analysis, in which primary attention is focused on expenditure and income elasticities, may serve only as a very rough first approximation in assessing the influence of aggregate demand in explaining industrial patterns. This is the case because "economic development" should be more broadly conceived than merely an expansion of per capita income. It must include additional attributes of economic progress - some the result of changes in per capita income, some largely independent of it. Demographic change is a case in point. ${ }^{4}$

Systematic changes in the rate of population growth, of ages, of average family size, and of urbanization (internal migration) are all a part of economic development. While each of these factors exerts an impact on the size and composition of demand, a theoretical examination of the nature of this influence or an appraisal of its importance in the context of an economic-development framework is largely lacking. ${ }^{5}$

The present study investigates several aspects of the relationship of demographic change and industrial demand. It is argued on theoretical grounds, and illustrated by reference to Philippine ex-

3. Chenery, op. cit.

4. While selected aspects of demographic change have been theoretically and empirically related to the level of per capita income, the association is frequently quite tenuous and indirect. See Irma Adelman, "An Econometric Analysis of Population Growth," American Economic Review, LIII (June 1963), 314-39; Kingsley Davis, "Population," in Technology and Economic Development, ed. Scientific American (New York: Knopf, 1963). Harvey Leibenstein, Economic Backwardness and Economic Growth (New York: Wiley, 1957). R. R. Nelson, "The Low-Level Equilibrium Population Trap," American Economic Review, XLIV (Dec. 1956), 894-908. United Nations, The Determinants and Consequences of Population Trends (New York: 1953).

5. An exception to this claim is the work of Ansley J. Coale and Edgar M. Hoover, Population Growth and Economic Development in Low-Income Countries (Princeton: Princeton University Press, 1958). 
perience, that the apparent unimportance of demand in explaining changes in industrial patterns may rest not on the relative weakness of Engel effects, but rather upon demographic influences which accompany economic progress. Indeed, in the Philippine case income elasticities explain a very small fraction of the total change in demand (primary versus "other" demand), perhaps as little as 10 per cent of the total. However, when demographic factors are incorporated into the analysis, not only does a much more complicated demand analysis emerge but also the analysis leads to a fuller appreciation of the nature and significance of the factors explaining changes in consumption patterns - and thereby industrial patterns - accompanying economic development.

Section II presents a model and a methodological approach in which demographic change is highlighted as an element in the level and composition of demand. Estimates of the variables and parameters included in the theoretical framework follow in Section III. Section IV presents an experiment which assesses the significance of accounting for population factors, taking the Philippines as a case study. We conclude with a statement of the implications of the analysis and empirical experimentation.

\section{The Model}

A simple model is developed below to identify the impact of selected demographic influences on the level and composition of demand. The focus is on three categories of change: alterations in the urban-rural distribution of the population (deriving from both differential natural growth rates and net internal migration), changes in average family size, and growth in the total number of families.

This model is designed to illustrate a general methodological approach to the examination of demographic factors influencing overall demand composition. It can thus be readily utilized in the context of several goods and alternative functional forms of Engel curves. Additionally, it can be expanded and modified to examine other categories of demographic changes, e.g., social or occupational mobility, variations in the age distribution, ${ }^{6}$ and so forth. In this

6. The present formulation omits this variable since the available Philippine data did not permit a treatment of age-specific variations in consumption. A detailed theoretical and empirical examination of the influence of a changing age distribution on economic growth is found in Allen C. Kelley, "Demographic Change and Economic Growth: Australia, 1861-1911," Explorations in Entreprencurial History, Vol. 5 (Spring, Summer 1968), pp. 11585. Consult also Allen C. Kelley and Jeffrey G. Williamson, "Household 
section only a linear demand function is presented since it sufficiently illustrates the methodology and underlying assumptions. The appendix contains the model applicable to the log-linear demand function.

Let the total demand $D$ for a good be broken into an urban and a rural component by the following identity:

$$
D=F_{r} D_{r}^{\prime}+F_{u} D^{\prime}{ }_{u}
$$

where $F_{r}$ and $F_{u}$ are the numbers of rural and urban families and $D^{\prime}{ }_{r}$ and $D^{\prime}{ }_{u}$ are the average per family demands for the good by rural and urban families. Assume that these demands are determined by the following linear demand functions:

$$
\begin{aligned}
& D^{\prime}{ }_{r}=a_{r}+\beta_{r} X^{\prime}{ }_{r}+\gamma_{r} f_{r}{ }_{r} \text { and } \\
& D^{\prime}{ }_{u}=a_{u}+\beta_{u} X^{\prime}{ }_{u}+\gamma_{*} f^{\prime}{ }_{u}
\end{aligned}
$$

where $X^{\prime}{ }_{r}$ and $X^{\prime}{ }_{1}$ are total per family consumption expenditures of the rural and urban sectors, and $f^{\prime}{ }_{r}$ and $f^{\prime}{ }^{\prime}$ are average family sizes in the rural and urban sectors. The parameters of the functions in (2) will be estimated below by disaggregation and using cross-section household data. ${ }^{7}$ The choice of total expenditure as the independent variable is based on the proposition that this measure is a better proxy for permanent income than total income and that permanent income is the relevant explanatory variable of both total expenditure and of its components. Additionally, total expenditure typically possesses a higher level of measurement accuracy in household surveys. ${ }^{8}$ Substituting (2) in (1) gives

$$
D=F_{r}\left(a_{r}+\beta_{r} X^{\prime}{ }_{r}+\gamma_{r} f_{r}^{\prime}\right)+F_{u}\left(a_{u}+\beta_{u} X^{\prime}{ }_{u}+\gamma_{u} f^{\prime}{ }_{u}\right) \text {. }
$$

Let $F=F_{r}+F_{u}$ be the total population of families; let $\mu$ be the fraction of total family growth taking place in the rural sector, excluding migration effects; and let $\phi$ be the rate of rural to urban

Savings Behavior in the Developing Economics: The Indonesian Case," Economic Development and Cultural Change (forthcoming).

In the near future the data constraints will be eliminated and the microeconomic data (Republic of the Philippines, Department of Commerce and Industry, Bureau of the Census and Statistics) (4,585 households) of the 1965 Philippine Statistical Survey of Households will be subjected to analysis in a joint research project "Consumer Behavior in the Philippines: An Econometric Analysis of Household Budgets," by Allen C. Kelley and Jeffrey G. Williamson.

7. To estimate the parameter values of (2) from cross-section information, the usual assumption that the parameters are identical across households is made.

8. Prais and Houthakker argue that "The use of family household consumption expenditure as a determining variable in the consumption function can be justified on the assumption that while consumption expenditure may depend in a complicated way on income expectations, the distribution of consumption expenditures among the various commodities depends only on the level of consumption expenditure." S. J. Prais and H. S. Houthakker, The Analysis of Family Budgets (Cambridge, England: Cambridge University Press, 1955), p. 81. 
migration of families. Then, letting an asterisk beside a variable indicate a time derivative

$$
\begin{aligned}
& F^{*}{ }_{r}=\mu F^{*}-\phi \text { and } \\
& F^{*}{ }_{u}=(1-\mu) F^{*}+\phi .
\end{aligned}
$$

If we assume that the sectoral distribution of household formation is proportional to the number of families residing in each sector, $\mu$ can be taken as the share of new households in the rural area.

Now taking the time derivative of (3), substituting expressions

(4) for $F^{*}{ }_{r}$ and $F^{*}{ }^{*}$ wherever they appear, and rearranging terms,

$$
\begin{aligned}
& D^{*}=\left[\mu\left(a_{r}+\beta_{r} X^{\prime}{ }_{r}+\gamma_{r} f^{\prime}{ }_{u}\right)+(1-\mu)\left(a_{u}+\beta_{u} \mathrm{X}^{\prime}{ }_{u}\right.\right. \\
& \left.\left.+\gamma_{u} f^{\prime}{ }_{u}\right)\right] F^{*} \quad \text { \{family units } \\
& +\left[\gamma_{r} F_{r} f^{\prime}{ }_{r}^{*}+\gamma_{u} F_{u} f^{\prime}{ }_{u}{ }^{*}\right] \quad \text { \{family size } \\
& +\left[\left(a_{u}-\alpha_{r}\right)+\left(\beta_{u}-\beta_{r}\right) X^{\prime}{ }_{u}+\left(\gamma_{u}-\gamma_{r}\right) X_{r}^{\prime}\right] \phi \\
& \text { \{rural to urban migration } \\
& +\left[\beta_{r} F_{r} \cdot X^{\prime}{ }_{r}^{*}+\beta_{u} F_{u} X^{\prime}{ }_{u}^{*}\right]
\end{aligned}
$$

\{average expenditure\}.

The bracketed terms in (5) represent, respectively, the portion of total expenditure growth on the commodity attributable to changes in the number of households, changes in the average family size, the rate of rural-urban migration, and the growth of the mean expenditure level. For each category except internal migration, the total effect can further be subdivided into the elements of change occurring in the urban and the rural sectors. Each term thus has a clear analytical and economic interpretation. ${ }^{9}$

It is seen that the impact of each element depends on the specific values of the behavioral parameters $\left(a_{r}, \boldsymbol{a}_{u}, \boldsymbol{\beta}_{r}, \boldsymbol{\beta}_{u}, \gamma_{r}\right.$, and $\left.\gamma_{u}\right)$ and on the level and change of the variables highlighted in the model (number of families, average family size, rate of rural-urban migration, and average expenditure). For example, if family size did not enter as a significant determinant of the household demand for the good, $\left(\gamma_{u}=\gamma_{r}=0\right)$, then the growth of average family size in either sector would have no influence on the demand for the good. Alternatively, if $\gamma_{u}$ or $\gamma_{r}$ did not equal zero and if average family size were changing, the influence on the composition of demand would depend on the rate of change in the average family size in each sector, on the size of the sector, and on the magnitude of the behavioral response as determined by the values of $\gamma_{u}$ and $\gamma_{r}$. In the linear formulation of the household expenditure equations the interpretation of the elements in the change, as represented in (5) above, is very straightforward.

9. An expression analogous to (5) above, but employing instead an exponential representation of household behavior, is presented in the Appendix. 
The interpretation of the "migration effect" must be made explicit. Since our basic model does not distinguish the recent migrant as behaving differently from the residents in the region to which he has moved, the "migration effect" can thus be considered as that proportion of the differential sectoral growth of population which arises from rural-urban migration. While one would ideally hope to investigate the behavior of the migrant group separately, data availability typically constrains this possibility. ${ }^{1}$ An approximation to the impact of actual migrant behavior can be made, however, by considering the range of possibile economic parameters determining consumption. This range would plausibly span the economic behavior prevailing in the area from which the migrant moved and that in which he settled. At one extreme the migrant would take with him the behavioral patterns of his previous residence. At the other extreme the migrant assumes immediately the attributes of his new residence. Finally, the most reasonable hypothesis would suggest that the rural (urban) migrant takes with him the behavioral response of his previous environment. Over time this response is transformed to that of the new location according to some specific time path, e.g., a distributed lag model. A more detailed analysis of migration behavior will be presented in the next section.

\section{The Model and Philippine Experience}

The model presented in (5) allows an assessment of four elements in the changing composition of demand for a given commodity. The behavioral parameters must be estimated and inserted into the formulation. Then with assumptions (or estimates) regarding the size and growth of the relevant variables (family size, number of families, rural-urban migration, and average total expenditures), the expression can be evaluated. This procedure involves a simple parametric exploration which is useful in obtaining a first approximation to the impact of demographic change on the composition of demand and, indirectly, on industrial patterns, in so far as domestic production is related (as it obviously would be in a closed economy) to domestic consumption.

The extensive empirical investigation required for such an ex-

1. In a study of household expenditure patterns among Massachusetts urban workers in 1875, Professor Williamson has found the "new" American immigrants, to a large degree, were very slow to adjust to American incomes, relative prices, and tastes. J. G. Williamson, "Consumer Behavior in the Nineteenth Century: Carroll D. Wright's Massachusetts Workers in 1875," Explorations in Entrepreneurial History, Vol. 4 (Winter 1967), pp. 98-135. 
periment is beyond the scope and objectives of this paper.2 It is possible, however, to suggest the nature of the procedures and to provide a preliminary appraisal of the significance of demographic factors by experimenting with (5) on a much more limited scale. Based on Philippine experience, two categories of expenditures will be examined: food $(f)$ and nonfood $(n)$. The relevant parameters are estimated with grouped, in contrast to microeconomic, observations.

\section{A. Estimates of the Parameters}

The data are taken from the 1961 Philippine Statistical Survey of Households (PSSH): Family Income and Expenditures. ${ }^{3}$ The sample, comprising 4,426 households, is examined in two parts: total urban, including metropolitan Manila (1,505 households), and rural $(2,921$ households). In the regressions below each observation is weighted by the number of households in its expenditure class. Table I presents the estimated parameters for both the linear and the log-linear formulations.

All but five of the parameters are significantly different from zero at the 95 per cent confidence level. Furthermore, the elasticity estimates $(\eta)$ at the mean expenditure level accord with both a priori expectations and the findings of Houthakker, ${ }^{4}$ Feraren, ${ }^{5}$ and others. ${ }^{6}$

A particularly interesting result is the rather wide urban-rural difference in the family size coefficients. There are theoretical reasons to expect such a deviation, however. The addition of another family member to the household has several influences. Using Houthakker's terminology, ${ }^{\top}$ there is an income effect, which results from the lower income of everyone in the family due to an additional member, and a specific effect, which derives from the additional con-

2. Such an investigation would necessarily involve a detailed breakdown of equation (5), the consideration of many functional forms appropriate to estimating the demand for various products, the estimation of the relevant behavioral parameters, an attempt to resolve the serious aggregation problems associated with the use of microeconomic data, and the performance of many experiments designed to assess both the nature of the model itself, and the factors highlighted in the analysis.

3. Republic of the Philippines, Department of Commerce and Industry, Bureau of the Census and Statistics, The Philippine Statistical Survey of Households (Manila, 1965).

4. Op. cit.

5. John B. Feraren, "The Use of Family Household Expenditures in Estimating Expected Demand in the Philippines," M.A. Thesis, University of the Philippines (Nov. 1963). cit.

6. Allen and Bowley, op. cit., Goreux, op. cit., Islam, op. cit., Leser, op.

7. Op. cit., p. 544 . 
sumption required for that particular member of the family. Scale economies in consumption explain in part the specific effect. The family size coefficient will vary inversely both with the scale economy effect and with the income elasticity of demand for the product.

Consider the case of food expenditures. It is seen from Table I that the expenditure elasticity for food is greater in rural than in

\section{TABLE I}

Linear and Log-Linear Engel Functions, and Mean Expenditure Elasticities $\left(\eta_{i j}\right)$ for Food and Nonfood Categories

(in pesos)

\begin{tabular}{|c|c|c|c|c|c|c|c|c|}
\hline & \multicolumn{4}{|c|}{$X=a+\beta X^{\prime}+\gamma F^{\prime}$} & \multicolumn{4}{|c|}{$\log X=\log a+\beta \log X^{\prime}+\gamma \log F^{\prime}$} \\
\hline & \multicolumn{2}{|c|}{ Rural } & \multicolumn{2}{|c|}{ Urban } & \multicolumn{2}{|c|}{ Rural } & \multicolumn{2}{|c|}{ Urban } \\
\hline & Food & Nonfood & Food & Nonfood & Food & Nonfood & Food & Nonfood \\
\hline$a$ & $\begin{array}{c}2.16 \\
(76.83)\end{array}$ & $\begin{array}{l}-2.16 \\
(76.83)\end{array}$ & $\begin{array}{c}-485.37 \\
(187.28)\end{array}$ & $\begin{array}{c}485.37 \\
(187.28)\end{array}$ & $\begin{array}{c}.99 \\
(.14)\end{array}$ & $\begin{array}{r}-2.95 \\
(.19)\end{array}$ & $\begin{array}{l}1.18 \\
(.09)\end{array}$ & $\begin{array}{r}-2.72 \\
(.06)\end{array}$ \\
\hline$\beta$ & $\begin{array}{c}.40 \\
(.02)\end{array}$ & $\begin{array}{c}.60 \\
(.02)\end{array}$ & $\begin{array}{c}.28 \\
(.02)\end{array}$ & $\begin{array}{c}.72 \\
(.02)\end{array}$ & $\begin{array}{c}.75 \\
(.05)\end{array}$ & $\begin{array}{l}1.30 \\
(.06)\end{array}$ & $\begin{array}{c}.67 \\
(.03)\end{array}$ & $\begin{array}{l}1.25 \\
(.02)\end{array}$ \\
\hline$\gamma$ & $\begin{array}{c}45.35 \\
(17.40)\end{array}$ & $\begin{array}{c}-45.35 \\
(17.40)\end{array}$ & $\begin{array}{l}174.09 \\
(34.06)\end{array}$ & $\begin{array}{r}-174.09 \\
(34.06)\end{array}$ & $\begin{array}{c}.19^{\mathrm{a}} \\
(.12)\end{array}$ & $\begin{array}{c}-.08^{a} \\
(.16)\end{array}$ & $\begin{array}{c}.409 \\
(.10)\end{array}$ & $\begin{array}{r}.00^{\mathrm{a}} \\
(.07)\end{array}$ \\
\hline$\eta$ & .65 & 1.51 & .58 & 1.39 & .75 & 1.30 & .67 & 1.25 \\
\hline
\end{tabular}

a Insignificantly different from zero at the 95 per cent confidence level.

urban areas. One explanation of this result which is consistent with both functional forms employed above is based on the premise that the variety and quantities of alternative goods available for consumption are greater in the city than on the farm. Thus, even at constant expenditure levels, urban competition for consumption by alternative goods is greater, and the resulting expenditure elasticities for food are less than on the farm.

The specific effect, based on scale economies in consumption, appears to be at variance with the results in Table I since one would expect economies of scale in the consumption of food to be greater in urban than in rural areas (and thus $\gamma_{r}>\gamma_{u}$ ). Economies arise from the purchase, storage, and preparation of food. While urbanrural differentials are difficult to justify in food preparation, it is plausible to argue that, given buying economies and greater availability of storage facilities in urban areas, economies would indeed be greater in the eity than on the farm. It should be noted, however, that with respect to nonfood items, the scale economy effect is consistent with the results. That is, consumer durables and social overhead capital, in which there are significant economies of con- 
sumption, bulk relatively greater in the urban than in the rural household budget.

With respect to food consumption, we would thus suggest that the results can be explained by a dominance of the income effect over the specific effect. With respect to nonfood expenditures, scale economies enter more significantly.

Three final points of interpretation should be made explicit. First, as with most cross-section studies, we do not account for the possible impact of regional price variations on differential urbanrural expenditure patterns. Second, the estimated parameters may be biased, given the interaction of family size and total expenditure. No attempt has been made to cope with possible error deriving from simultaneous equation bias. Third, since the results are not invariant to the particular expenditure grouping available in the PSSH summary tables, confidence in the specific parameter estimates could be significantly increased by the use of micro data. However, given the rather wide commodity groupings employed (i.e., food and nonfood), it will be seen below that our results are insensitive to wide changes in the parameters. We thus feel justified, at this stage, to return to and focus on the main problem - the implications of demographic change on demand patterns.

\section{B. The Course of Demographic and Economic Change}

Four elements of demographic and economic change are represented in equation (5). The object of this section will be to provide estimates of these variables which approximate an average year's experience between 1956 and 1966 utilizing, as the base Philippine population, the number and composition of households in the 1961 PSSH: Family Income and Expenditures.

The growth in family size is based on the average annual change between 1956 and 1961 reported in the PSSH. Urban growth, .0575 persons per year, is considerably more rapid than rural growth, .0136. This result derives in part from differing age distribution in the two areas, originating largely from rural-urban migration. The average Philippine family increased by .0286 members per year.

An estimate of the annual expansion in the number of Philippine families can be found utilizing (1) an assumed population growth of 3.33 per cent per year, ${ }^{8}$ and $(2)$ the above annual change in the size of the average family. The resulting rate is 2.82 per cent.

8. Republic of the Philippines, Department of Commerce and Industry, Bureau of the Census and Statistics, Demography Division, Population Projection of the Philippines: 1960-1975 (Manila, 1964). 
To transform this expression into levels of change per year, the 1961 PSSH sample of 4,426 households is again employed, yielding $F^{*}$ of 125 per year.

The rate of internal migration is considerably more difficult to estimate. Since no data on internal migration are available, two separate proxies are utilized. The first is based on the pre-1961 experience. The second assumes a rate consistent with the government projections for the 1966-71 period. Consider first the pre-1961 period.

Estimates have been compiled of the annual rate of urban growth between the 1948 and 1961 censuses for two separate definitions of urban areas: ${ }^{9}$ (1) Rizal province and Manila (4.71 per cent per year), and (2) the seventeen largest cities excluding Manila, Quezon and Pasay, but including the provinces of Manila and Rizal (4.31 per cent per year). If this range of rates continues in the 1960's and the rate of family growth is 2.82 per cent, the annual proportion of the population migrating to urban areas ranges from .25 to .35 per cent. ${ }^{1}$ This estimate is, in fact, a lower limit with respect to the 1960's in which, if the changing agricultural, nonagricultural labor force composition can be taken as an indication of shifts toward urban employment, a 1 per cent shift per year would be a more reasonable approximation. ${ }^{2}$

An upper limit can be represented by the government's "projected" shift toward industrial and tertiary employment, as found in the "Socio-Economic Development Program for the Fiscal Year 1966-67 to the Fiscal Year 1969-70." 3 Even though total employment is expected to grow by 3 per cent between 1967 and 1971, agricultural employment is anticipated to remain approximately unchanged. Assuming constant utilization rates, these estimates are consistent with an average annual shift into nonagricultural (and urban) employment, and a resulting rate of rural-urban migration, approaching 2 per cent. The analysis below employs migration rates of $1 / 2$ per cent, 1 per cent and 2 per cent with the presumption that $1 / 2$ and 2 per cent represent outer limits and that 1 per cent is the most plausible estimate for the mid-sixties.

The growth of total real family expenditures has ranged be-

9. Census of the Philippines: 1960, Population, Housing, op. cit.

1. No attempt has been made to account for the effect of net international migration.

2. See also Robert F. Huke, Shadows on the Land (Manila: Carmelo \& Bauermann, 1963).

3. Philippine National Economic Council, "Socio-Economic Development Program for the Fiscal Fear 1966-67 to the Fiscal Year 1969-70" (Manila, 1966), mimeo. 
tween $1 / 2$ and 1 per cent over the period 1956-62. The "SocioFconomic Development Program" estimates that these rates will continue at least until 1969-70. Since the model of (5) requires an explicit assumption regarding the distribution of the improvement in living standards as between the urban and rural population, three possibilities are considered: the total increase is enjoyed by the urban population only, by the rural population only, or by the two populations equally.

\section{Demand Patterns, Demographic Change, ANd Economic Growth}

We are now able to identify the relative significance of several factors influencing the composition of demand in the Philippines. Estimates of both the behavioral parameters and the trend values for the structural variables have been provided. Substituting these estimates into equation (5), a first approximation to the level and composition of demand may be obtained. The results, presented in Table II, may be interpreted as follows. Given various assumptions regarding the growth of per family expenditures, population, family size, and migration, what would be the level of demand for food and nonfood products, postulating respectively a linear and loglinear demand function for these commodity classifications.

Consider first the importance of each element in explaining the level, as distinct from the composition of demand. Several striking results appear. First, and not too surprising, the most important factor in the Philippines case appears to be total population growth. Second, depending upon the rate of urbanization, internal migration may, under likely circumstances, enter more importantly into demand than per family expenditure growth. Third, the combined influence of two relatively unheralded elements in demand, internal migration and family size growth, turn out to possess a greater aggregate impact than the expansion in mean family expenditure. And finally, the combined demographic factors are overwhelmingly the crucial explanatory variable. Given probable trends for the near future, i.e., increasingly internal migration and an expansion of population growth, the margin is likely to increase.

Even more interesting is the influence of demographic change on the composition of demand. While expenditure elasticities have dominated the literature in identifying growth industries and Engel functions have often been cited as a major determinant of the shift out of agriculture and into industrial production, a close analysis 


\section{TABLE II}

Increase in Demand Projected for Food and Nonfood Products, with Indicated Values for Expansion in Total Per Family Expenditures, Family Size, RuralUrban Migration, and Total Number of Families

(in pesos)

\begin{tabular}{|c|c|c|c|c|}
\hline \multirow[b]{2}{*}{ Component of Demand } & \multicolumn{2}{|c|}{$\begin{array}{l}\text { Projections with } \\
\text { Linear Model }\end{array}$} & \multicolumn{2}{|c|}{$\begin{array}{l}\text { Projections with } \mathrm{Log} \\
\text { Linear Model a }\end{array}$} \\
\hline & Food & Nonfood & Food & Nonfood \\
\hline \multirow{2}{*}{\multicolumn{5}{|c|}{$\begin{array}{l}\text { Per Family Expenditure Growth } \\
1 \text { per cent per year, distributed } \\
\text { to the }\end{array}$}} \\
\hline & & & & \\
\hline 1. urban sector, totally & 7,634 & 19,342 & 8,965 & 16,026 \\
\hline $\begin{array}{l}\text { 2. urban and rural sectors, } \\
\text { equally }\end{array}$ & 14,235 & 25,430 & 16,216 & 15,369 \\
\hline 3. rural sector, totally. & 20,837 & 31,518 & 23,467 & 30,737 \\
\hline \multicolumn{5}{|l|}{$\begin{array}{l}1 / 2 \text { per cent per year, distrib- } \\
\text { uted to the }\end{array}$} \\
\hline 1. urban sector: totally & 3,817 & 9,671 & 4,483 & 8,013 \\
\hline $\begin{array}{l}\text { 2. urban and rural sectors, } \\
\text { equally }\end{array}$ & 7,090 & 12,715 & 8,108 & 11,690 \\
\hline 3. rural sector, totally. & 10,419 & 15,759 & 11,733 & 15,369 \\
\hline \multicolumn{5}{|l|}{ Increase in Total Number of } \\
\hline Families & 123,083 & 101,477 & 123,183 & 104,124 \\
\hline Family Size Growth & 16,866 & $-16,866$ & 8,685 & $0^{b}$ \\
\hline \multicolumn{5}{|l|}{ Rural-Urban Migration at } \\
\hline 1. $1 / 4$ per cent per year & 6,212 & 8,803 & 5,938 & 7,486 \\
\hline 2. $1 / 2$ per cent per year & 12,424 & 17,606 & 11,877 & 14,972 \\
\hline 3. 1 per cent per year & 24,847 & 35,212 & 23,753 & 29,944 \\
\hline 4. 2 per cent per year & 49,696 & 70,425 & 47,506 & 59,889 \\
\hline
\end{tabular}

a While the estimated family size coefficient is significant for rural food and urban food at the 85 and 95 per cent confidence levels, respectively, the estimated parameters for the nonfood category are not statistically different from zero. On the latter we have, for purposes of demand projections, assumed that the coefficient is zero.

h Given the above assumption regarding the nonfood family size coefficients, this expression is zero. See the Appendix.

of the results in Table III presents a significantly different interpretation of the demand trends consistent with the Philippine process of economic growth. For simplicity this table provides the information relating to the linear formulations only, presenting the estimates for plausible assumptions regarding real expenditure growth ( $1 / 2$ per cent per year, shared equally by the two sectors) and ruralurban migration ( 1 per cent per year). Column (3) indicates the percentage spending rate on food due to the indicated component, e.g., expenditure growth, internal migration, and so forth. Given an actual aggregate spending rate on food of 53.82 per cent deriving from all component elements in demand in 1961, then a single component average less (greater) than the aggregate rate (i.e., column (4) greater (lessi than one) represents a situation in which the 


\section{TABLE III}

The Role of Selected Variables in Influencing the Proportion of Total Expenditure on Food ${ }^{a}$

\begin{tabular}{|c|c|c|c|c|}
\hline \multirow[b]{2}{*}{ Conponent of Demand } & \multicolumn{2}{|c|}{ Projections for } & \multirow{2}{*}{$\begin{array}{c}\text { Average } \\
\text { Alloca- } \\
\text { tion Ratio } \\
1 /(1+2) \\
(3)\end{array}$} & \multirow{2}{*}{$\begin{array}{c}\text { Col. (3) } \\
53.82 \\
(4)^{\mathrm{b}}\end{array}$} \\
\hline & $\begin{array}{c}\text { Food } \\
\text { (1) }\end{array}$ & $\underset{\text { Nonfood }}{\text { Non }}$ & & \\
\hline $\begin{array}{l}\text { Expenditure Growth ( } 1 / 2 \text { per cent per } \\
\text { year, distributed to the urban and } \\
\text { rural sectors equally) }\end{array}$ & 7,090 & 12,715 & 35.80 & .665 \\
\hline \multicolumn{5}{|l|}{ Demographic Factors } \\
\hline Total Population Growth & 123,083 & 101,477 & 54.81 & 1.018 \\
\hline Family Size Growth & 16,866 & $-16,866$ & - & - \\
\hline $\begin{array}{l}\text { Rural-Urban Migration ( } 1 \text { per cent } \\
\text { per year) }\end{array}$ & 24,847 & 35,212 & 41.37 & .769 \\
\hline Total Demographic & 164,796 & 119,823 & 57.90 & 1.076 \\
\hline Total Demand & 171,886 & 132,538 & 56.46 & 1.049 \\
\hline
\end{tabular}

a This table is based on the linear demand functions.

b The average Philippine expenditure on food in 1961 was 53.82 per cent. If column (3) is greater (less) than this ratio (i.e., column (4) is greater (less) than unity), then the indicated component is operating to shift relative demand toward (away from) food products.

demand forces initiate a decrease (an increase) in the relative allocation on food consumption.

Expenditure elasticities play the expected role. The expenditure average rate ( 35.80 per cent) is considerably less than the 1961 average, yielding a ratio of .665 , the strongest single demand force moving in this direction. On the other hand, the influence of expenditure growth is less than 10 per cent of the total.

Of the three demographic factors, rural-urban migration exerts, in direction, the same influence as expenditure elasticities. It must be underscored, however, that the values of the migration parameters which are used to obtain the results in Table III represent a somewhat extreme assumption regarding the behavior of migrants. Migrants are assumed to take on the behavioral and economic characteristics of the area in which they reside. However, recall that Williamson has found with respect to nineteenth century American experience that there may be a considerable lag in the adjustment process. ${ }^{4}$ If the latter qualification is incorporated into the model, migration would serve much less as a force shifting demand away from food consumption and, under plausible assumptions, may even work in the opposite direction.

4. Williamson, op. cit. 
Total population growth is largely "neutral" in its specific demand compositional effect (i.e., the value of column $4 \approx 1.00$ ). In the aggregate, however, given its overwhelming importance in the total, total population serves strongly to attenuate movements (in either direction) away from the previous composition of demand. An examination of the last two lines of the table bears out this conclusion.

Not only do the demographic factors, in total, move the economy in an opposite direction from that dictated by the process of economic growth, narrowly conceived (an expansion of per capita income and expenditure), but also, even when combined with the impact of expenditure elasticities, the net direction remains the same. And if we modify our assumption regarding the speed of the migrant's response to the new environment, then far from providing an engine of structural change into industrial growth and out of agriculture, the result is one in which demand factors, in the aggregate, severely attenuate or even reverse this course of development.

While it is outside the immediate scope of this paper to assess the applicability of the Philippine findings to the developing countries in general, it would be useful to suggest certain theoretical and empirical considerations which would be relevant to appraising this issue.

Given the paucity of estimates of Engel functions for the developing nations, one can only speculate on the generality of the estimated parameter values for the Philippines. It is plausible that differences in parameter values between urban and rural areas would decrease as countries become more urbanized. At its current level of urbanization, the Philippines might thus underestimate the impact of internal migration on demand patterns in the other less developed countries. However, direct evidence on rates of internal migration in the developing countries is almost nonexistent so that a complete comparison of Philippine experience with that of other countries cannot be successfully undertaken.

The rate of population growth in the Philippines is relatively high. Thus estimates of the impact of this factor on demand patterns can be considered as above the average of the less developed countries. At present, however, much of Latin America and Asia is experiencing population growth rates approaching that of the Philippines.

Finally, the growth of per capita expenditure in the Philippines is considerably lower than that of the typical less developed 
country." This fact suggests that the Philippine case understates the influence of Engel's law.

We conclude that the Philippine case is likely to overstate the relative importance of demographic factors for the "typical" less developed country. Nevertheless, the rising population growth rates in most of these countries, coupled with the possible decline in per capita consumption growth rates associated with the population explosion, imply that the results illustrated for the Philippines may become increasingly applicable through time.

\section{Implications and Conclusions}

Since population growth and an expansion of family size appear to be an integral part of the early phases of economic development, the rate of change in the composition of final demand - and hence the pace of industrialization, another index of economic progress may, as a result, proceed quite slowly. Nations that strive for industrialization should appreciate the role which demographic change plays in this process. An obvious government policy consistent with industrialization would be to curtail rapid population growth. If the country is unable to operate effectively in the area of population growth, several additional interesting policies are suggested by our analysis.

The shift away from demand for agricultural products, ceteris paribus, proceeds more rapidly (1) the greater the rate of total per family expenditure growth, (2) the more rapid the rate of internal migration into urban areas, and (3) the more the relative benefits of economic growth are distributed to the urban population. The first two of these factors increase the weight of the demand influences operating toward a shift out of agriculture; the third follows from the observation that the average allocation ratio on food diminishes as the relative distribution of expenditure growth to the urban population increases. If, as is likely to be the case, a rapid movement toward urbanization will diminish population growth, the demand factors moving the economy toward a modern industrial base will be strengthened.

Thus, while we do not claim to have discovered another "population trap," a comparison of our findings with those deriving from

5. For the thirty-three countries for which data are available on the levels of consumption expenditure, rates of inflation, and population change for the period from 1958-64, the computed average growth of real per capita consumption yields 1.54 per cent. 
the models of Leibenstein and Nelson would seem appropriate. ${ }^{6}$ These population-trap models, couched in a unisectoral framework, have as their dependent variable the level of per capita income. They demonstrate that rapid population growth may inhibit, unless some "critical minimum level" is reached, further expansions of wellbeing. The "big push" is an implied development strategy.

In our own multisectoral growth framework, if we assume that the composition of demand exerts an influence on future industrial patterns, and if we accept that a shift of economic production into industrial and away from agricultural activities is another measure of economic progress (and possibly even more fundamentally, a "cause" of rising per capita income), then population growth may move the economy away from economic progress. A significant initial push toward industrialization, involving rapid internal migration, may offset the rapid growth of population.

Finally, our results are consistent with Chenery's findings which point to a predominance of supply factors in explaining industrial patterns. The demand-originating elements of his model are based primarily on income changes. Our findings suggest that demographic factors may, under plausible conditions existing in many developing nations, be an even more important element explaining changes in demand. Furthermore, the net influence of income and demographic elasticities may, in many cases, be largely offsetting, thus resulting in a relatively small demand effect as found by Chenery. If we are willing to disaggregate and to examine explicitly the role of demographic factors, then demand may reenter as a potentially significant element in explaining industrial progress. Furthermore, the disaggregated analysis adds several degrees of freedom for government policy. Clearly these conclusions argue strongly both for a closer inquiry into the role of demand, particularly in a disaggregated framework, and for a more explicit integration of demographic change into the economic models of growth and development.

\section{Appendix}

Another widely used hypothesis of expenditure behavior is the simple exponential function of the form

$$
\text { (1A) } \quad D^{\prime}=a X^{\prime} \beta f^{\prime} \gamma
$$

This expression can be employed in a manner analogous to the linear formulation incorporated in $(5)$. The resulting expression is presented below as $(2 \mathrm{~A})$.

6. Leibenstein, op. cit. Nelson, op. cit. 
(2A) $\quad D^{*}=\left[\mu\left(a_{r} X^{\prime}{ }_{r}{ }_{r} f^{\prime}{ }_{r} \gamma_{r}\right)+(1-\mu)\left(a_{u} X^{\prime}{ }_{u}{ }^{\left.\left.\beta_{u} f^{\prime}{ }_{u} \gamma_{u}\right)\right] F^{*}}\right.\right.$

\{family units\}

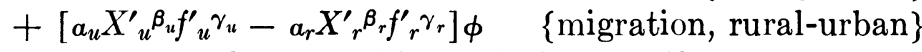

$+F_{r}\left(a_{r} \beta_{r} X^{\prime}{ }_{r}^{\left(\beta_{r}-1\right)}{f^{\prime}}_{r} \gamma_{r}\right) X_{r}^{\prime}{ }^{*}+F_{u}\left(a_{u} \beta_{u} X^{\prime}{ }_{u}{ }^{\left(\beta_{u}-1\right)}{f^{\prime}}_{u} \gamma_{u}\right) X_{u}^{\prime}{ }_{u}{ }^{*}$

\{average expenditure\}

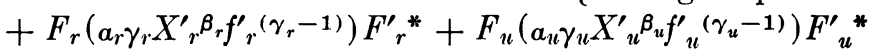

\{family size $\}$.

UNIVERSITY OF WISCONSIN 